\title{
SYNTHESIS AND CHARACTERIZATION OF
}

\section{OCTAAZATRICYCLOTETRACOSANE (OCTC) MACROCYCLIC COMPLEXES OF NI (II), CU (II) TRANSITION METAL IONS DERIVED FROM 1, 3-DIAMINOPROPANE CONTAINING AZA LIGANDS}

\author{
Sangeeta Sahu \\ Department of Applied Chemistry, Bhilai Institute of Technology, Kendri, New Raipur-493661 (Chhattisgarh) India \\ sangeetasahu76@gmail.com
}

\begin{abstract}
This paper deals with the synthesis and characterization of macrocyclic ligand and its complex compound. Template condensation of chlorocarbons such as 1,1,2,2-tetrachloroethane with 1,3-diaminopropane in presence of nickel (II) or copper (II) yielded the corresponding metal complexes such as 3,7,10,14,15,19,20,24- octaazatricyclotetracosane (OCTC). The macrocyclic ligands and their complexes have been characterized by elemental analysis, molecular weight determination, conductance, IR and NMR spectral studies. The magnetic moments, along with electronic spectral data suggested hexa coordinated state for Nickel, its geometry is outer orbit octa hedral and tetra coordinated state for copper, its geometry is square planner.Conductivity data suggests that they behave as electrolytes. The formulation of the complexes has been established on the basis of chemical composition.
\end{abstract}

Keywords: Ni (II), Cu (II), Transitional Macrocyclic Complex, Synthesis, Spectroscopy.

\section{INTRODUCTION}

Curtis reported the first of a number of pioneering template reaction for macrocyclic systems which were published in the period 1960 to 1965 [1].In the Curtis synthesis, a yellow crystalline product was observed to result from the reaction of $\left[\mathrm{Ni}(1,2 \text {-diaminoethane })_{2}\right]^{2-}$ and dry acetone. The yellow product was shown to be a mixture of the isomeric macrocyclic complexes. 5,5,7,12,12,14-hexamethyl-1,4,8,11tetraazacyclotetradeca-1,14 diene [3]. In this remarkable cyclization reaction, formation of bridges between the two 1,2-diaminoethane moieties involves condensation of two acetone molecules per bridge [2]. Here, a hydrogen-bonding network may act as a template for the reaction and also serve to stabilize once it is formed. A revised synthesis of the metalfree ligands has been published [4].

This paper describes synthesis and characterization of macrocyclic complexes of nickel (II) and copper (II) derived from1, 3-diaminopropane .The 1, 3-diaminopropane has been condensed with 1,1,2,2-tetrachloroethane in presence of a metal-ion in different molar ratios as mentioned in their synthesis.

\section{EXPERIMENTAL}

In view of the importance of macro cyclic chemistry the $\mathrm{Ni}$ (II), $\mathrm{Cu}$ (II) complexes of new categories of aza macro cyclic were synthesized. Template condensation of chloro carbon such as 1,1,2,2-tetrachloroethane with 1,3-diaminopropane in presence of $\mathrm{Cu}$ (II),Ni (II) yield the corresponding metal complex of the following macro cyclic legend 3,7,10,14,15,19,20,24-octaazatricuclo[7.5.5.52.8] tetracosane (OCTC) (Figure 1).

Solvents and reagents used in the synthesis of the nickel (II) and copper (II) complexes were reagent grade and were used without further purification.

2.1 Synthesis of the Nickel (II) Complex of 3, 7, 10, $14, \quad 15, \quad 19, \quad 20, \quad 24-$ Octaazatricuclo $\quad[7.5 .5 .52 .8]$ Tetracosane (OCTC)

Nickel hydroxide $95.00 \mathrm{~g}, 53.92$ (mmole) was added to stir mixture of 1, 3-diaminopropane (7.99 g, $107.78 \mathrm{mmole})$ and 1 , 1, 2, 2- tetrachloroethane (9.05 g, $53.92 \mathrm{mmole})$ in $200 \mathrm{ml}$ butanol. The mixture was then refluxed for $4 \mathrm{hrs}$. After being refluxed about $5 \mathrm{~min}$. the mixture changed to blue turbid solution containing a small quantity of the green precipitate. The whole mixture turned into a blue turbid solution after being refluxed for $4 \mathrm{~h}$. It was then cooled treated with $150 \mathrm{ml}$ of water and aqueous bluish-violet solution was separated and the green precipitate and colourless non-aqueous butanol layer were rejected. Condensation and refrigeration of the solution gave crude, sticky violet crystals of [Ni2 (OCTC) (H2O) 4] $\mathrm{Cl} 4.5 \mathrm{H} 2 \mathrm{O}$. The sticky material was removed by treating the 
product with ether-benzene $(1: 1)$ mixture on filter paper. The product was recrystallized to remove traces of white residue. Pure product was crystallized from the resulting solution. Violet crystals were finally washed with ether and dried, yield $10.2 \mathrm{~g}$ (Figure 2).

\subsection{Synthesis of the Copper (II) Complex of 3, 7, 10,}

$14, \quad 15, \quad 19, \quad 20, \quad 24-$ Octaazatricuclo $\quad[7.5 .5 .52 .8]$ Tetracosane (OCTC)

The cyclization reaction involving 1, 3-diaminopropane (7.60 g, 102.52 mmole) was carried out by refluxing the mixture in $200 \mathrm{ml}$ butanol. The deep blue mixture changed into a greenish-blue solution after continuous heating for $3 \mathrm{~h}$. The greenish-blue solution was treated with water and filtered. The brown residue in small quantity was rejected. The violet aqueous layer of the filtrate containing the macrocyclic product was separated from the non-aqueous wine-red layer. Concentration and refrigeration of the aqueous layer yielded violet crystals soluble in methanol and water. The crystals were washed with acetone followed by ether, yield $7.32 \mathrm{~g}$. (Figure 3)

\section{RESULTS AND DISCUSSION}

\subsection{Synthesis}

The nickel (II) complex of $3,7,10,14,15,19,20,24-$ octaazatricuclo [7.5.5.52.8] tetracosane (OCTC) derived from 1:2:1 molar mixture of nickel hydroxide 1, 3-diaminopropane and 1, 1, 2, 2,-tetrachloroethane contain two nickel ions in the ligand cavities, where each metal is coordinated to for donars. The two molecules of 1:2 nickel-ammine complexes formed at the initial stage condensed with two molecules of 1, 1, 2, 2tetrachloroethane yielding the corresponding dinuclear complex.

In the extension of 1, 3-diaminopropane and 1, 1, 2, 2tetrachloroethane condensation to copper (II) ion under the similar reactant ratio, the macrocyclic OCTC is again generated. But, the ligand encapsulates four copper ions in its cavity. Four compared to 1:2 copper-ammine complex where each copper ion is coordinated to two aza groups of the ligands.

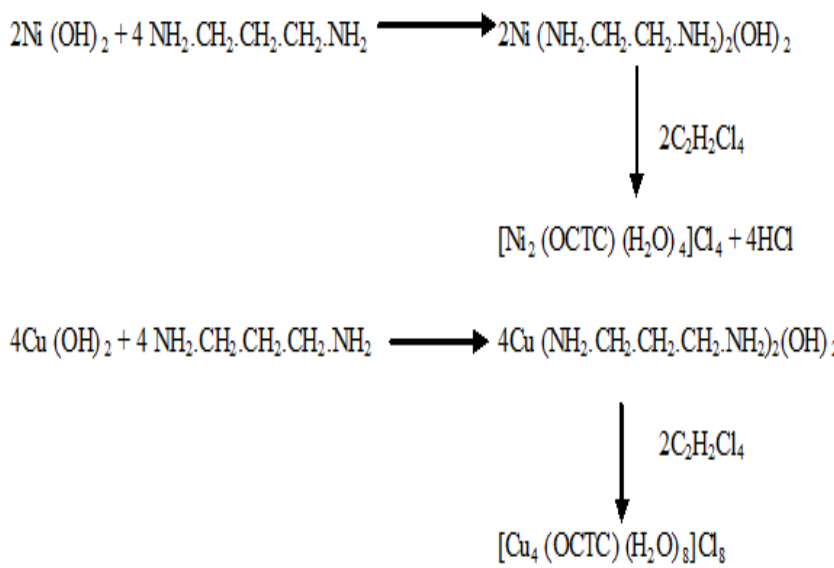

\subsection{Chemical Analysis}

Microanalysis for carbon, hydrogen and nitrogen were carried out at the regional sophisticated instrumentation centre, central drug research institute (CDRI) Lucknow. The metal content was determined by EDTA titration The ionizable chloride ions in the compounds were determined by conductanctric titration using $0.01 \mathrm{M}$ ligand /complex and $0.1 \mathrm{M} \mathrm{AgNO}_{3}$ solution. (Table 1.1)

\subsection{Physical Measurements}

Conductivity data of the complex was recorded using their $0.01 \mathrm{M}$ aqueous solution, with the help of a DDR Conductivity meter type 304. A Jeol D-300 (El/Cl) spectrometer was used for obtaining the mass spectra of the ligand hydrochlorides of low molecular weight. Infrared spectra in the range $4000-250 \mathrm{~cm}^{-1}$ were recorded by Perkin Elmer infrared spectrometer in $\mathrm{KBr}$ pellets. FTIR spectra of a number of compound were recorded by Shimadzu 8201 PC (4000-350 $\mathrm{cm}^{-1}$ ) infrared spectrophotometer. The pmr spectra were taken in $\mathrm{D}_{2} \mathrm{O}$ solution and recorded on bruker DRX300 (300 MHz. PT NMR) using tetra methylsilane as an internal standard. (Table 1.2)

\subsection{Infrared Spectra}

The infrared spectrum of $\left[\mathrm{Ni}_{2}(\mathrm{OCTC})\left(\mathrm{H}_{2} \mathrm{O}\right)_{4}\right] \mathrm{Cl} 4.5 \mathrm{H}_{2} \mathrm{O}$ includes the absence of bands due to the $\mathrm{NH}_{2}$ group. A very weak but very sharp band attributed to only a secondary amine appears at $3150 \mathrm{~cm}^{-1}$. This suggests the presence of a strong but sharp band at $1594 \mathrm{~cm}^{-1}$. A medium but very band at 1065 $\mathrm{cm}^{-1}$ may be assigned in the $v(\mathrm{C}-\mathrm{H})$ vibration. Medium but sharp scissoring band are seen at 2920,2870 and $1438 \mathrm{~cm}^{-1}$, respectively. The bands at 1470, 1380, 1328, 1278, 1160, $1100,1008,900,878,364$ and $319 \mathrm{~cm}^{-1}$ are associated with the skeletal vibration of the whole complex. A medium but sharp band at $478 \mathrm{~cm}^{-1}$ is attributed to the nickel nitrogen bond. Coordination of water is supported by the presence of a very strong but very broad band at $3250 \mathrm{~cm}^{-1}$ followed by a very weak band at $800 \mathrm{~cm}^{-1}$ assigned to stretching and rocking 
vibrations of the water molecule, respectively. A band at 638 $\mathrm{cm}^{-1}$ is attributed to the (Ni-O) vibration of coordinatated water.

In the complex the $\mathrm{N}-\mathrm{H}$ stretching mode of the secondary amine is seen at $3110 \mathrm{~cm}^{-1}$ while the position of the $\mathrm{N}-\mathrm{H}$ bending vibration is at $1580 \mathrm{~cm}^{-1}$. A very weak very sharp band at $1050 \mathrm{~cm}^{-1}$ is associated with $(\mathrm{C}-\mathrm{H})$. Coordination of the ligand through the nitrogen is evident by a medium but very band at $488 \mathrm{~cm}^{-1}$ The bands for coordinated water are seem at $3225,812,670$ and $606 \mathrm{~cm}^{-1}$ and are attributed to $(\mathrm{O}$ $\mathrm{H})$, rocking and wagging vibration of $\mathrm{H}_{2} \mathrm{O}$ molecule and $(\mathrm{Cu}-$ O) respectively [5].

The OCTC hydrochloride spectrum is different in several respects from the spectrum of its nickel or copper complex. The major difference occurs in the $1400-400 \mathrm{~cm}^{-1}$ region where bands due to water molecules or metal coordinate bond with nitrogen and oxygen are absent. The ligand hydrochloride exhibit a series of weak or very weak but generally sharp bands at 2775,2644,2495,2407,2366 and $2302 \mathrm{~cm}^{-1}$, and a prominent band at $2019 \mathrm{~cm}^{-1}$ (medium, sharp) associated with $>\mathrm{NH}_{2} \mathrm{Cl}$ groups. Such bands are absent in the OCTC complexes. The cyclic nature of the metal-free ligand is demonstrated by the similarly of its amine bands with those of the nickel or copper complex molecule [6]. A corresponding $(\mathrm{N}-\mathrm{H})$ vibration is seen at $1600 \mathrm{~cm}^{-1}$ strong/medium/weak bands for $\mathrm{C}-\mathrm{H}$ asymmetric and symmetric stretching and scissoring mode appear at 3008,2845 and $1402 \mathrm{~cm}^{-1}$ are also characteristic of the whole ligand molecule [7]. (Table 1.3)

\subsection{Nuclear Magnetic Resonance Spectra}

Additional structural evidence for these ligands has been obtained from the pmr spectra of their hydrochlorides. The spectrum of OCTC hydrochloride [8] is slight shifting of the signals. The alpha and bet methylenes resolved into broad triplets and pentlet, respectively, are centred at 3.16 and 2.01 $\mathrm{ppm}$. Their positions of resonances are in agreement with the integrated of the signals (proton ratio 16:8). The $\mathrm{NH}_{2}$ protons. A sharp peak at $3.44 \mathrm{ppm}$ expected for methylene protons is observed in the pmr spectrum of OCTC hydrochloride. Also, a broad singlet at $4.95 \mathrm{ppm}$ may be assigned to $\left(\mathrm{CH}+\mathrm{NH}_{2}\right)$ proton resonance [8].

\section{Nickel Complexes of OCTC}

Very complex multiplets in the region $3.09-1.57 \mathrm{ppm}$ in the spectrum of nickel complex with OCTC are unintepretable. But, a broad peak observed in the region 5.12-4.38 ppm is expected for protons of coordinated water and the $\mathrm{NH}$ group [9].

\subsection{Mass Spectra OCTC Systems}

Determination of molecular weight by mass spectra of the compounds OCTC.8HCl has been very useful in completing their characterization. The corresponding peaks in OCTC. $8 \mathrm{HCl}$ are very close to their molecular ions. The slightly low $\mathrm{m} / \mathrm{z}$ values in these systems may be associated with the mass lost $(\mathrm{H})$ due to fragmentation of the molecular ions. The mass loss corresponds to the sum of the masses of few $\mathrm{H}$ atoms and two and seven molecules of $\mathrm{HCl}$ attached with the macrocycles, respectively, through weak coordinate bonds [10].

\subsection{Solubility, Conductivity and Other Data}

The nickel complexes $\left[\mathrm{Ni}_{2}\right.$ (OCTC) $\left.\left(\mathrm{H}_{2} \mathrm{O}\right)_{4}\right] \mathrm{Cl} 4.5 \mathrm{H}_{2} \mathrm{O}$ have low decomposition points whereas others are thermally stable and decompose near their melting points. In addition, attachment of only one chloride ion through an ionic bond in the nickel (II)-OCTC complex gives indirect information on the metal-chloride ion coordinate linkage of the other chloride ion. Also, the colour of the nickel (II)-OCTC complex is Violet (bluish-violet). Whereas the complexes of copper (II) are Violet (brown liquid).All the complexes are highly soluble in water due to their ionic nature [11].Most of them are soluble in many other polar solvents, like methanol, ethanol, DMF, DMSO etc [12]. Similarly, the molar conductance $\left(\mathrm{ohm}^{-1} \mathrm{~cm}^{2} \mathrm{~mol}^{-1}\right)$ obtained for $\left[\mathrm{Ni}_{2}(\mathrm{OCTC})\left(\mathrm{H}_{2} \mathrm{O}\right)_{4}\right] \mathrm{Cl}_{4} \cdot 5 \mathrm{H}_{2} \mathrm{O}$ (498) or $\left[\mathrm{Cu}_{4}(\mathrm{OCTC})\left(\mathrm{H}_{2} \mathrm{O}\right)_{8}\right] \mathrm{Cl}_{8} \cdot 6 \mathrm{H}_{2} \mathrm{O}$ (886) are consistent with formation of these complexes[13].

\section{CONCLUSIONS}

The present investigation deals with the synthesis and characterization of macrocyclic ligands and its transition metal complexes. On the basis of elemental analysis, molecular weight determination, conductance, IR and NMR spectral studies, the nature as well as to some extent, structure and stereochemistry of macrocyclic ligands have been suggested. The above procedures outlined for the preparation of the resultant macrocyclic complexes are facile and appear to proceed smoothly. This is used as electro catalyst in fuel cell, enhances the electrical conductivity. It should prove useful for investigation of metal containing-biological molecules such as metalloenzymes and their catalytic activity for industries. This catalyst use for major change in Pharmaceutical education Nahata catalyst which act as an efficient reusable heterogeneous catalyst, this catalyst use in drug discovery and drug development

\section{REFERENCES}

[1]. N F Curtis, J.Chem.Soc.1960, 4409.

[2]. N F Curtis,D A House,Chem. Ind. 1961,1708.

[3]. N F Curtis, Y M Curtis, H K J Powell, J.Chem. Soc. (A) 1966,1015

[4]. R W Hay, G A Lawrance, N F Curtis, J.Chem. Soc. Dalton Trans, 1975,591

[5]. R e Shephered, Coord.Chem.Rev, 2003, 247,147.

[6]. Z M Zaki, S S Haggag, A A Soayed, Spectrosc. Lett; $1989,31,757$ 
[7]. E C Constable, Coord.Chem. Rev; 1989, 93,205

[8]. M N Patel, N H Patel, P K Panchal, D H Patel, Synth, React. Inorg. Met.Org. Chem.2004, 34, 873.

[9]. R N Prasad, M Agarwal, R George, Synth. React. Inorg. Met. Org. Chem.2004, 34, 943.

[10]. B Singh, K K Narang, R Srivastava, Synth.React.Inorg.Me, Org.Chem.2002, 32, 1561.
[11]. J Rogan, D Poleti, L Karanovic, Bogdanovic, A S De Bire, Polyhefron,2000, 19,1415.

[12]. H K Shin, K M Chin, J Farkas, M J H Smith, T T Kodas, E N Duesler, Inorg.Chem, 199231,424.

[13]. G Ambrosi, M Formica, V Fusi, P Rossi, Inorg. Chem, 2007, 46, 309

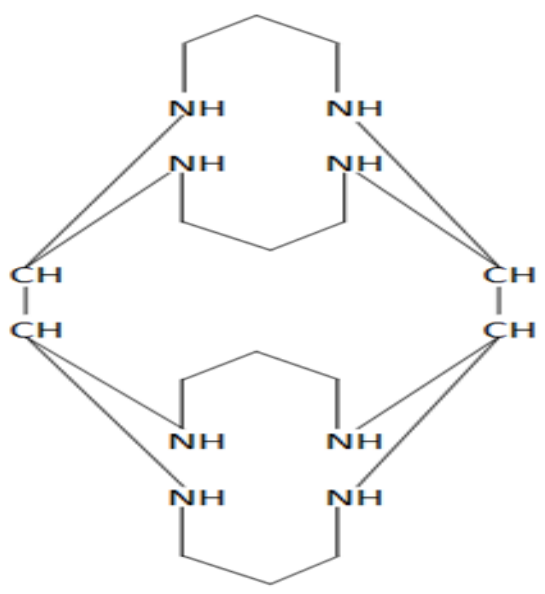

OCTC

Figure 1: Structure of OCTC

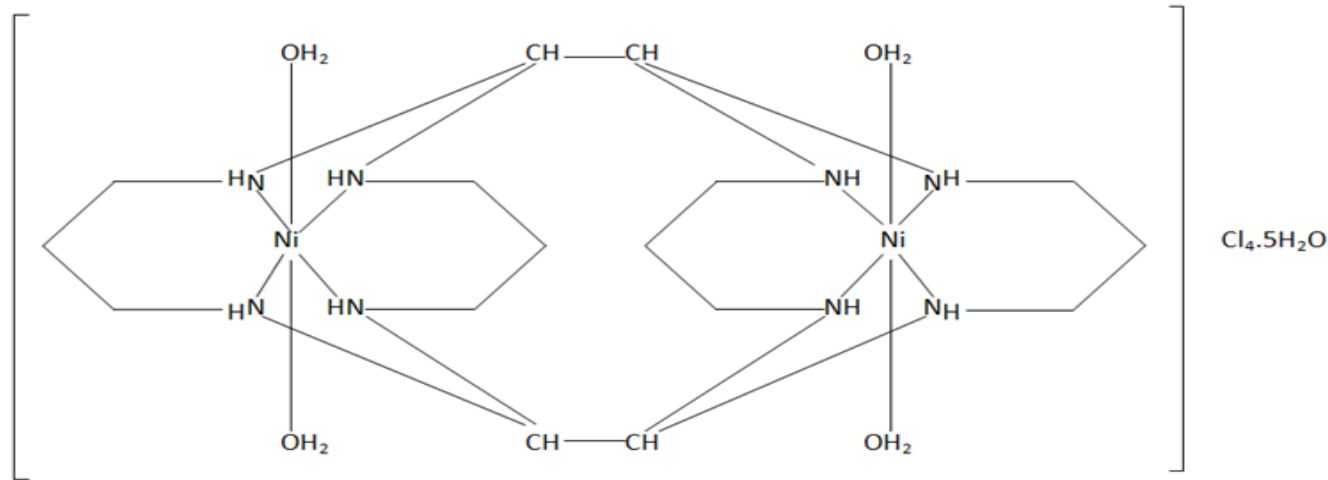

$\mathrm{Ni-OCTC}$

Figure 2: Structure Ni-OCTC 


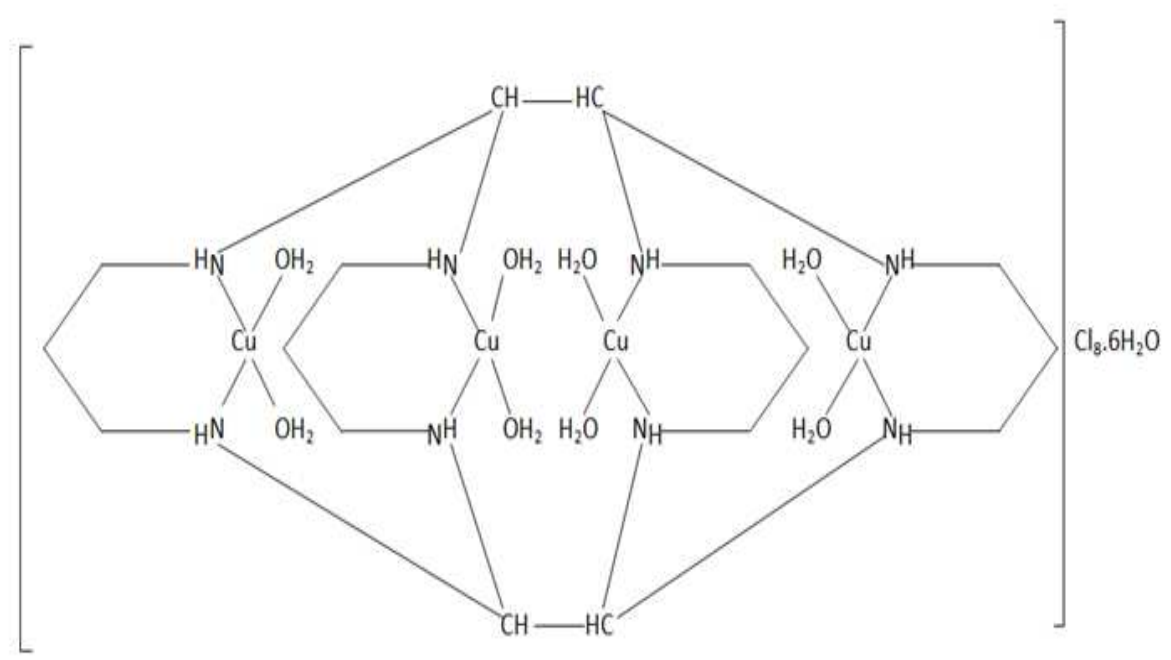

Cu-OCTC

Figure 3: Structure of Cu-OCTC

Table 1.1 Analytical and physical data of the Nickel(II) Complex of 2,5,7,10,13,16,18,21,23,26,29,32Dodecaazatricyclo [20.10.0.0] dotriacontane (DOCD) Macrocyclic Compounds derived from Triethylenetetramine

\begin{tabular}{|c|c|c|c|c|c|c|c|c|c|}
\hline \multirow[t]{2}{*}{ compound } & \multirow{2}{*}{$\begin{array}{l}\text { Colour } \\
\text { (colour } \\
\text { at D.P.) }\end{array}$} & \multirow{2}{*}{$\begin{array}{l}\text { Yield } \\
(\%), \\
\text { (D.P. } \\
\text { V } \\
\text { M.P. } \\
\left({ }^{\circ} \mathrm{C}\right)\end{array}$} & \multirow{2}{*}{ 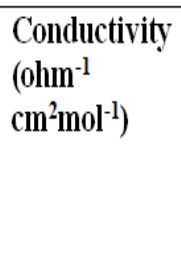 } & \multicolumn{5}{|c|}{ \% Found ( Calculated) } & \multirow{2}{*}{$\begin{array}{l}\text { Mol. } \\
\text { wt. } \\
\text { Found } \\
\text { (Calcu } \\
\text { lated) }\end{array}$} \\
\hline & & & & $\mathrm{C}$ & $\mathrm{H}$ & $\mathrm{N}$ & $\mathrm{Ni}$ & $\mathrm{Cl}$ & \\
\hline $\begin{array}{l}{\left[\mathrm{Ni}_{2}(\mathrm{OCTC})\right.} \\
\left.\left(\mathrm{H}_{2} \mathrm{O}\right)_{4}\right] \mathrm{Cl}_{4} \cdot 5 \mathrm{H}_{2} \mathrm{O} \\
\\
\mathrm{Ni}_{2} \mathrm{C}_{16} \mathrm{H}_{54} \mathrm{~N}_{8} \mathrm{O}_{9} \\
\mathrm{Cl}_{4}\end{array}$ & $\begin{array}{l}\text { Violet } \\
\text { (bluish- } \\
\text { violet) }\end{array}$ & $\begin{array}{l}49.7 \\
(122)\end{array}$ & 498 & $\begin{array}{l}25.29 \\
(25.22)\end{array}$ & $\begin{array}{l}7.14 \\
(7.16)\end{array}$ & $\begin{array}{l}14.75 \\
(14.71)\end{array}$ & $\begin{array}{l}15.46 \\
(15.41)\end{array}$ & $\begin{array}{l}18.56 \\
(18.61)\end{array}$ & $(762.0)$ \\
\hline
\end{tabular}


Table 1.2 Analytical and physical data of the Copper(II) Complex of 2,5,7,10,13,15,18,21,23,26,29,32-

Dodecaazatricyclo[20.10.0.0] dotriacontane (DOCD) Macrocyclic Compounds derived from Triethylenetetramine

\begin{tabular}{|c|c|c|c|c|c|c|c|c|c|}
\hline \multirow[t]{2}{*}{ compound } & \multirow{2}{*}{$\begin{array}{l}\text { Colour } \\
\text { (colour } \\
\text { at D.P.) }\end{array}$} & \multirow{2}{*}{$\begin{array}{l}\text { Yield } \\
(\%), \\
\text { (D.P.v } \\
\text { M.P.) }\left({ }^{0} \mathrm{C}\right)\end{array}$} & \multirow{2}{*}{$\begin{array}{l}\text { Conductivity } \\
\left(0 \mathrm{hm}^{-1}\right. \\
\left.\mathrm{cm}^{2} \mathrm{~mol}^{-1}\right)\end{array}$} & \multicolumn{5}{|c|}{ \% Found ( Calculated) } & \multirow{2}{*}{$\begin{array}{l}\text { Mol. } \\
\text { wt. } \\
\text { Found } \\
\text { (Calculat } \\
\text { ed) }\end{array}$} \\
\hline & & & & $\mathrm{C}$ & $\mathrm{H}$ & $\mathrm{N}$ & $\mathrm{Cu}$ & $\mathrm{Cl}$ & \\
\hline $\begin{array}{l}{\left[\mathrm{Cu}_{4}(\mathrm{OCTC})\right.} \\
\left.\left(\mathrm{H}_{2} \mathrm{O}\right)_{8}\right] \mathrm{Cl}_{8} . \\
6 \mathrm{H}_{2} \mathrm{O} \\
\mathrm{Cu}_{4} \mathrm{C}_{16} \mathrm{H}_{64} \mathrm{~N} \\
{ }_{8} \mathrm{O}_{14} \mathrm{Cl}_{18}\end{array}$ & $\begin{array}{l}\text { Violet } \\
\text { (brown } \\
\text { liquid) }\end{array}$ & $\begin{array}{l}50.0 \\
(185)\end{array}$ & 886 & $\begin{array}{l}17.06 \\
(17.00)\end{array}$ & $\begin{array}{l}5.70 \\
(5.72)\end{array}$ & $\begin{array}{l}9.88 \\
(9.91)\end{array}$ & $\begin{array}{l}22.54 \\
(22.48)\end{array}$ & $\begin{array}{l}25.00 \\
(25.08)\end{array}$ & $(1130.6)$ \\
\hline
\end{tabular}

Table 1.3 Important IR Band of the Macrocyclic Compound from 1, 3-Diaminopropane

\begin{tabular}{|c|c|}
\hline Compound & IR Bands $\left(\mathrm{cm}^{-1}\right)$ \\
\hline$\left[\mathrm{Ni}_{2}(\mathrm{OCTC})\left(\mathrm{H}_{2} \mathrm{O}_{4}\right] \mathrm{Cl}_{4} \cdot 5 \mathrm{H}_{2} \mathrm{O}\right.$ & $\begin{array}{l}3250 \text { (vs,vb),3150(vw,vsp),2920(m,vsp),2870(m,sp), } 1595(\mathrm{~s}, \mathrm{sp}), 1470 \text { (m,vsp), } \\
1438(\mathrm{w}, \mathrm{vsp}), 1380(\mathrm{~s}, \mathrm{vsp}), 1328(\mathrm{~m}, \mathrm{vsp}), 1160(\mathrm{~s}, \mathrm{vsp}), 1065(\mathrm{~m}, \mathrm{vsp}), 1008(\mathrm{~s}, \mathrm{vsp}) \\
900(\mathrm{~s}, \mathrm{vsp}), 878(\mathrm{vw}, \mathrm{sp}), 800(\mathrm{vw}, \mathrm{sp}), 638(\mathrm{~s}, \mathrm{sp}), 478(\mathrm{~m}, \mathrm{sp}), 478(\mathrm{vw}, \mathrm{sp}), 319(\mathrm{~m}, \mathrm{sp})\end{array}$ \\
\hline$\left[\mathrm{Cu}(\mathrm{OCTC})\left(\mathrm{H}_{2} \mathrm{O}\right)_{8}\right] \mathrm{Cl}_{8} \cdot 6 \mathrm{HO}$ & $\begin{array}{l}3225 \text { (vs,vp),3110(w,vsp),2920(m,vsp),2860(w,vsp),1580(vs,sp),1430(w,vsp), } \\
1360(\mathrm{vs}, \mathrm{b}), 1310 \text { (vs,sp),1270(s,vsp),1160(w,vsp),1110(vs,vsp),1012(vs,vsp), } \\
900 \text { (s,vsp),870(w,sp),812(vw),670(m,vsp),606(m,vsp),488(m,vsp),392(w,sp), } \\
350 \text { (m,sp) }\end{array}$ \\
\hline
\end{tabular}

